\title{
Selection of the all-time best World XI Test cricket team using the TOPSIS method
}

\author{
Shankar Chakraborty*, Vidyapati Kumar and K.R. Ramakrishnan
}

Department of Production Engineering, Jadavpur University, Kolkata, India

\begin{tabular}{l}
\hline C H R O N I C L E \\
\hline Article history: \\
Received January 15, 2018 \\
Received in revised format: \\
January 16, 2018 \\
Accepted April 18, 2018 \\
Available online \\
April 18, 2018 \\
\hline Keywords: \\
Test cricket \\
World XI Test team \\
MCDM \\
TOPSIS \\
Rank
\end{tabular}

\begin{abstract}
A B S T R A C T
The aim of this paper is to apply the technique for order preference by similarity to ideal solution (TOPSIS) as a multi-criteria decision making tool to form the all-time best World XI Test cricket team while taking into consideration over 2600 cricketers participated in Test matches for more than 100 years of cricket history. From the voluminous database containing the performance of numerous Test cricketers, separate lists are first prepared for different positions in the batting and bowling orders consisting of manageable numbers of candidate alternatives while imposing some constraints with respect to the minimum number of innings played (for batsmen), minimum number of tests played (for wicketkeepers and bowlers), and minimum numbers of runs scored and wickets taken (for all-rounders). The TOPSIS method is later adopted to rank those shortlisted cricketers and identify the best performers for inclusion in the proposed World XI Test team. The best World Test cricket team is thus formed as Alastair Cook (ENG) (c), Sunil Gavaskar (IND), Rahul Dravid (IND) (vc), Sachin Tendulkar (IND), Shivnarine Chanderpaul (WI), Jacques Kallis (SA), Adam Gilchrist (AUS) (wk), Glenn McGrath (AUS), Courtney Walsh (WI), Muttiah Muralitharan (SL) and Shane Warne (AUS).
\end{abstract}

\section{Introduction}

Cricket is considered as one of the major international sports with respect to participants, spectators and media interest. Today, this game is played in three different formats, i.e. Test, One-day International (ODI) and Twenty-Twenty (T20) at the international level. But, Test cricket is the oldest format among the three. It has also the longest form in the world of sports and is internationally acclaimed due to its highest playing standard. In Test cricket, two teams consisting of 11 players in each play a four-innings match, which may last up to five days. It is generally considered to be the most complete examination of the playing ability and endurance of the participating cricketers. In a Test, the relative strengths of the two competing sides are really tested (Lemmer, 2011).

The first Test match was played between England and Australia in 1877, which was eventually won by Australia by 45 runs. South Africa became the third team to play Test cricket in 1888-89, when they hosted a tour by an under-strength England side. Since the first Test match, there have been more than 2,000 Tests played by 10 teams, i.e. England (ENG), Australia (AUS), South Africa (SA), New Zealand (NZ), India (IND), Pakistan (PAK), Sri Lanka (SL), West Indies (WI), Bangladesh (BAN) and 
Zimbabwe (ZIM). In 2017, Afghanistan (AFG) and Ireland (IRE) were also awarded the Test status to become the $11^{\text {th }}$ and $12^{\text {th }}$ full members of the International Cricket Council (ICC). The frequency of Tests has steadily increased due to the increase in the number of participating countries, and willingness of the concerned cricket boards to maximize their revenue.

There are some interesting facts and figures in Test cricket. In Test cricket, the most successful team, with respect to both wins and win percentage, is Australia, having won 362 of their 773 Tests (46.83\%). The least successful team is Bangladesh who has struggled since their introduction to Test cricket in 2000. Donald Bradman of Australia scored the most runs in a Test series, had the maximum number of double centuries and was a part of the record fifth wicket partnership. His batting average was as high as 99.94. In 1956, England spin bowler Jim Laker took 19 wickets for 90 runs. While taking 10 wickets for 53 runs in the second innings, he became the first bowler to capture all the ten wickets in a Test match innings. West Indies batsman Brian Lara has the highest individual score (400 not out against England in 2004) in Test cricket. Pakistan's Misbah-ul-Haq holds the record of the fastest test half century scoring 50 runs from 21 balls. On the other hand, New Zealand's Brendon McCullum scored 100 runs from 54 balls to hold the record for the fastest Test century. Sri Lankan spinner Muttiah Muralitharan is the highest Test wicket-taker with 800 wickets. India's Sachin Tendulkar has the distinction of having the tally of 15,921 runs in Test cricket. The Test record for most number of dismissals (555) by a wicketkeeper is held by Mark Boucher of South Africa, while the record for most catches (210) by a fielder is held by Rahul Dravid of India (Kimber, 1993).

The process of team selection in Test cricket is a complex decision making problem, being influenced by numerous factors, like the player's individual performance, optimal combination of the players, their physical fitness, playing conditions, strengths and weaknesses of the opponent, and confidence of the selection committee on the players. The performance of a Test cricket team also depends on the quality and fairness of the game, strategies adopted by the coaches and captain; moreover on the involvement and support of the spectators. These above-mentioned factors significantly improve the chances of win of a Test cricket team with an optimal combination of players. There are also many constraints that play key roles in selecting cricketers for a Test team. The manual team selection procedure may have several demerits, like personal liking and disliking, biasness towards a particular player, personal grievances between the team selection committee and players, and social and political pressures. An ill-selected Test cricket team may often lead to failure and for this, the selection committee would become responsible to the spectators/cricket lovers. It also affects the loyalty and morale of the cricketers, resulting in poor performance in a Test match. A sub-optimal/poor team selection which is often responsible for reduced motivation and zeal of the team members thus must have to be avoided. It is always a better approach to employ a scientific tool with strong and valid mathematical foundation for the most befitting Test cricket team selection in less time with minimum complexities.

Beaudoin and Swartz (2003) proposed a new measure for evaluating the performance of batsmen and bowlers in One-day cricket. Barr and Kantor (2004) presented a two-dimensional framework consisting of strike rate and probability of getting out for having a useful, direct and comparative insight into batting performance in One-day International cricket games. Ovens and Bukiet (2006) proposed a novel mathematical modelling approach to compute the expected performance of a cricket batting order in an innings and applied it to quantify the influence of batting order in a One-day cricket game based on the available data. Swartz et al. (2006) applied simulated annealing for finding out the optimal or nearly optimal batting order for the Indian One-day cricket team. Sathya and Jamal (2009) adopted genetic algorithm to compose an optimal cricket team from a set of 50 Indian players, and claimed that it could be applied for any multi-player game while just modifying the corresponding fitness function. Ahmed et al. (2011) applied non-dominated sorting genetic algorithm (NSGA-II) to optimize the overall batting and bowling strength of a cricket team, and find team members in it. The algorithm was employed on a set of players auctioned in Indian Premier League (IPL), 4th edition, while considering their T20 statistical data as the performance parameters. Kamble et al. (2011) demonstrated the application of a 
cricket team selection procedure from a set of Indian players in complex situations using analytic hierarchy process (AHP). Aqil Burney et al. (2012) applied genetic algorithm to find out the optimal solution for the problem of cricket team selection and formation, and verified its applicability on a group of top-performing Pakistani cricket players for Test team selection. The proposed team selection process took into account the number of wins and losses, and recent performance of the players in last few matches. Daniyal et al. (2012) adopted individual and moving range control charts for evaluating the batting performance of some of the selected cricketers. Bhattacharjee and Saikia (2014) proposed a composite index measure to evaluate the performance of cricketers irrespective of their expertise, and then applied a 0-1 integer programming approach to form an optimal cricket team. Saikia et al. (2016) pointed out that the selection of an optimal squad in cricket had been a complex decision making problem, introduced a measure to quantify the performance of cricketers into a single numerical value and validated the proposed approach while taking data from the $5^{\text {th }}$ edition of IPL. Irvine and Kennedy (2017) identified some key performance indicators that would most significantly affect the outcome of an international T20 cricket match. It was concluded that total number of dot balls bowled, total number of wickets taken and run rate would mainly dictate the result of a T20 cricket match.

It is observed from the above-cited literature review that the application of mathematical tools and techniques in the domain of optimal cricket team selection is really limited. The AHP method and genetic algorithm were mainly utilized for the formation of the best National level Test and One-day cricket teams. It is also noticed that till date, no fruitful endeavour has been put forward to mathematically decide the optimal composition of the Test cricket team for any of the participating countries. Thus, there is an ample scope to deploy any of the existing multi-criteria decision making (MCDM) methods to compose the best National Test cricket team. An MCDM method basically deals with the evaluation and identification of the best course of action/alternative in presence of several mutually conflicting criteria/attributes. Since the inception of Test cricket in 1877, hundreds of players have participated in this sport for their respective countries and some of them have achieved unforgettable traits due to their remarkable contributions in Test cricket. Now, the question always arises in mind that what will the optimal composition of a Test cricket team if all the participated and participating players are taken into account simultaneously. Thus, the objective of this paper is set to compose the all-time best World XI Test team considering all the players from the world of cricket while employing technique for order preference by similarity to ideal solution (TOPSIS) which has already been proven as an efficient MCDM tool for solving complex decision making problems.

\section{TOPSIS method}

The TOPSIS method (Hwang \& Yoon, 1981) is an MCDM tool which basically converts multiple attributes of a decision making problem into a single performance response value. It has been emerged out as an effective MCDM method because it involves less number of parameters, has high consistency and less computational effort. It is based on the notion that the best chosen alternative should have the shortest Euclidean distance from the positive-ideal solution, and the farthest from the negative-ideal solution. The positive-ideal solution is a hypothetical solution for which all the attributes correspond to their maximum values in the database, whereas, the negative-ideal solution is that hypothetical solution where all the attributes receive minimum values. This method thus provides a more realistic form of modelling as it allows trade-offs between various criteria, where a poor result in one criterion can be balanced by a good result with respect to another criterion. The procedural steps of TOPSIS method for selecting the best course of action from a set of feasible alternatives in presence of multiple conflicting criteria are presented as below:

a) Based on the set objectives, identify the pertinent evaluation criteria and a set of alternatives fulfilling those criteria.

b) With $m$ number of alternatives and $n$ number of criteria, a decision/evaluation matrix is developed depicting the performance of all the alternatives with respect to the considered criteria. 
$D=\left[\begin{array}{cccc}x_{11} & x_{12} & \ldots & x_{1 n} \\ x_{21} & x_{22} & \ldots & x_{2 n} \\ \ldots & \ldots & \ldots & \ldots \\ x_{m 1} & m_{m 2} & \ldots & m_{m n}\end{array}\right] \quad(i=1,2, \ldots, m ; j=1,2, \ldots, n)$

where $x_{i j}$ is the performance measure of $i^{\text {th }}$ alternative against $j^{\text {th }}$ criterion.

c) From the original decision matrix, the normalized decision matrix is derived using vector normalization procedure to make it dimensionless with comparable elements.

$$
r_{i j}=\frac{x_{i j}}{\sqrt{\sum_{i=1}^{m} x_{i j}^{2}}}
$$

where $r_{i j}$ is the normalized value of $x_{i j}$.

d) Using AHP or entropy method (Rao, 2007), determine the priority weight (relative importance) $\left(w_{j}\right)$ for each of the criteria.

e) Obtain the weighted normalized matrix.

$$
v_{i j}=r_{i j} \times w_{j} \quad(i=1,2, \ldots, m ; j=1,2, \ldots, n)
$$

f) Obtain the positive-ideal (best) and the negative ideal (worst) solutions using the following equations:

$$
\begin{aligned}
& A^{+}=\left\{v_{1}^{+}, v_{2}^{+}, \ldots, v_{n}^{+}\right\}, \\
& A^{-}=\left\{v_{1}^{-}, v_{2}^{-}, \ldots, v_{n}^{-}\right\},
\end{aligned}
$$

where $A^{+}$denotes the positive-ideal solution and $A^{-}$expresses the negative-ideal solution. For the $j^{\text {th }}$ beneficial criterion, $v_{j}^{+}=\max \left\{v_{i j}, i=1,2, \ldots, m\right\}$ and $v_{j}^{-}=\min \left\{v_{i j}, i=1,2, \ldots, m\right\}$. Similarly, for the $j^{\text {th }}$ nonbeneficial criterion, $v_{j}^{+}=\min \left\{v_{i j}, i=1,2, \ldots, m\right\}$ and $v_{j}^{-}=\max \left\{v_{i j}, i=1,2, \ldots, m\right\}$.

g) Obtain the separation measures. The separations of each alternative from the positive-ideal and negative-ideal solutions are calculated by the corresponding Euclidean distances, as given in the following equations:

$$
\begin{aligned}
& S_{i}^{+}=\sqrt{\sum_{j=1}^{n}\left(v_{i j}-v_{j}^{+}\right)^{2}}, \quad i=1,2, \ldots, m \\
& S_{i}^{-}=\sqrt{\sum_{j=1}^{n}\left(v_{i j}-v_{j}^{-}\right)^{2}}, \quad i=1,2, \ldots, m
\end{aligned}
$$

h) The relative closeness of a particular alternative to the ideal solution is estimated as follows:

$$
P_{i}=\frac{S_{i}^{-}}{S_{i}^{+}+S_{i}^{-}}
$$

i) The alternatives are now arranged in descending order of their $P_{i}$ values. The alternative with the highest $P_{i}$ value is identified as the most appropriate choice.

An excellent review on the applications of TOPSIS method in diverse fields of technological and managerial decision making is available in Behzadian et al. (2012), Tlig and Rebai (2017) and Bagheri et al. (2018). 


\section{Selection of the all-time best World XI Test cricket team}

As the objective of this paper is to compose the all-time best World XI Test team while taking into account all the players from the world of cricket applying TOPSIS method, it becomes the first task to decide about the structure of that team. Like the other National level cricket teams, this World XI Test team also consists of five batsmen (including two openers), one wicketkeeper, one all-rounder, two fast bowlers/pacers and two spinners. In a cricket team, the openers or opening batsmen are those two players who bat first in the innings, i.e. at the number 1 and 2 positions. The role of these two openers in the team is extremely important as they can only provide a good and solid start to the innings. They must be psychologically strong as they have to face the new ball at the start of the innings. At the beginning of an innings, the new ball is hard, moves fast, bounces high, swings in air and seams around unpredictably. As these early conditions are usually in favour of the bowling team, the openers must have patience, sound batting skill, defensive attitude and ability to adjust quickly with the condition of the pitch. They would have the determination to stay longer in the crease to protect the batsmen further down the batting order. If one of them loses his wicket early, it may impose tremendous pressure on the succeeding batsmen. It is often said that an opener needs to be a batter who wants to be an opening batsman. For a Test team, it is always preferred to have a left-hand and right-hand combinations of the openers because of the disruption it can cause to the opponent bowlers trying to establish the correct line and length at the start of the innings.

It is an extremely difficult task to identify the two best openers for the proposed World Test XI cricket team as there are hundreds of players who opened their Test innings for their respective countries. It is thus always better to reduce the total number of Test openers to a manageable figure based on some predetermined threshold criterion. Based on this perception, in this paper, a list of 21 opening batsmen is prepared in Table 1 who opened at least 140 Test innings for their countries. This list contains seven openers from England, four from Australia, three from South Africa, two each from India, Sri Lanka and West Indies, and one from New Zealand, There are no openers in this list from Pakistan, Bangladesh and Zimbabwe as none of their openers fulfils the criterion of playing at least 140 innings as an opening batsman. The performance of all these 21 shortlisted openers is now evaluated based on 12 pivotal criteria, i.e. number of innings (INN), total runs scored (RUN), number of times bowled (BWD), number of times caught by the fielders (CGT), number of times caught behind the wicket (CB), number of times of leg before the wicket (LBW), number of other modes of dismissal (ODM), average run (AVG), number of fifties scored (50s), number of hundreds/centuries scored (100s), number of outs without scoring a single run (DUCK) and the highest score (HS). The other modes of dismissal include stump out, run out, hit wicket, handed the ball and obstructed the field. A cricketer's batting average is the total number of runs scored divided by the number of times he has been out. In the HS column, an asterisk represents that the particular opener remained not out in that innings. Among these 12 performance measures for the openers, BWD, CGT, CB, LBW, ODM and DUCK are the nonbeneficial/cost criteria requiring their lower values, whereas, the remaining six are the beneficial criteria where their higher values are always desired. The pertinent information/statistics for all the considered Test cricket players are accumulated from various web sources, like www.howstat.com, www.espncricinfo.com, www.cricbuzz.com etc. Each of these considered criteria has its individual relative importance on the final selection decision which can only be estimated while employing AHP or entropy method. The criteria weights measured using AHP method are often biased being influenced by the subjective judgements of the decision makers while developing the relevant pair-wise comparison matrices. Thus, it is always preferred to augment entropy method to determine the weights of the considered criteria as it is based on the amount of information available in the form of a decision/evaluation matrix and its relationship with importance of the criterion. The main advantage of this method is that it estimates the criteria weights from the data given in the decision matrix and is independent of the views of the concerned decision makers (Xu, 2004). It basically measures the uncertainty associated with random phenomena of the information presented in the decision matrix. For selecting the top two openers from a set of 21 alternative choices, the corresponding weights for 
the 12 considered criteria are calculated as $0.128,0.125,0.081,0.059,0.040,0.068,0.055,0.099,0.090$, $0.099,0.056$ and 0.100 respectively. It can be clearly observed that the entropy method provides maximum importance (weight) to the number of innings played by a particular opener and total number of runs scored by him. These weights are provided in the last row of Table 1. Now, based on the procedural steps of TOPSIS method, the decision matrix of Table 1 is first normalized using the vector normalization procedure from which the corresponding weighted normalized matrix is developed. From this matrix, the corresponding positive-ideal and negative-ideal solutions are identified, and the distances of each alternative opener from these two solutions are estimated. The relative closeness of a particular alternative (TOPSIS score) to the ideal solution is then calculated based on which all the 21 openers are subsequently ranked.

Table 1

List of openers with minimum 140 Test innings

\begin{tabular}{|c|c|c|c|c|c|c|c|c|c|c|c|c|c|c|c|c|}
\hline Sl. No. & Player & CUN & INN & RUN & BWD & CGT & $\mathrm{CB}$ & LBW & ODM & AVG & $50 \mathrm{~s}$ & $100 \mathrm{~s}$ & DUCK & HS & Score & Rank \\
\hline 1. & Mark Taylor & AUS & 186 & 7525 & 26 & 65 & 36 & 30 & 16 & 43.5 & 40 & 19 & 5 & $334^{*}$ & 0.492 & 8 \\
\hline 2. & Mark Waugh & AUS & 209 & 8029 & 30 & 78 & 47 & 32 & 5 & 41.82 & 47 & 20 & 19 & $153^{*}$ & 0.463 & 11 \\
\hline 3. & Justin Langer & AUS & 182 & 7696 & 23 & 69 & 42 & 28 & 8 & 45.27 & 30 & 23 & 11 & 250 & 0.483 & 10 \\
\hline 4. & Matthew Hayden & AUS & 184 & 8625 & 21 & 88 & 22 & 26 & 13 & 50.74 & 29 & 30 & 14 & 380 & 0.564 & 3 \\
\hline 5. & Geoffrey Boycott & ENG & 193 & 8114 & 30 & 70 & 34 & 27 & 9 & 47.73 & 42 & 22 & 10 & $246^{*}$ & 0.526 & 5 \\
\hline 6. & Graham Gooch & ENG & 215 & 8900 & 36 & 70 & 45 & 50 & 8 & 42.58 & 46 & 20 & 13 & 333 & 0.505 & 7 \\
\hline 7. & Michael Atherton & ENG & 212 & 7728 & 32 & 74 & 59 & 35 & 5 & 37.7 & 46 & 16 & 20 & $185^{*}$ & 0.428 & 16 \\
\hline 8. & Michael Vaughan & ENG & 147 & 5719 & 22 & 55 & 41 & 17 & 3 & 41.44 & 18 & 18 & 9 & 197 & 0.432 & 14 \\
\hline 9. & Marcus Trescothick & ENG & 143 & 5825 & 25 & 55 & 39 & 9 & 5 & 43.8 & 29 & 14 & 12 & 219 & 0.442 & 13 \\
\hline 10. & Andrew Strauss & ENG & 178 & 7037 & 25 & 72 & 45 & 25 & 5 & 40.91 & 27 & 21 & 15 & 177 & 0.423 & 17 \\
\hline 11. & Alastair Cook ${ }^{* *}$ & ENG & 263 & 11579 & 29 & 95 & 71 & 49 & 4 & 46.69 & 55 & 31 & 8 & 294 & 0.643 & 1 \\
\hline 12. & Sunil Gavaskar & IND & 214 & 10122 & 33 & 87 & 54 & 17 & 17 & 51.12 & 45 & 34 & 12 & $236^{*}$ & 0.583 & 2 \\
\hline 13. & Virender Sehwag & IND & 180 & 8586 & 31 & 82 & 30 & 21 & 10 & 49.34 & 32 & 23 & 16 & 319 & 0.518 & 6 \\
\hline 14. & John Wright & $\mathrm{NZ}$ & 148 & 5334 & 21 & 65 & 37 & 12 & 6 & 37.83 & 23 & 12 & 7 & 185 & 0.413 & 18 \\
\hline 15. & Gary Kirsten & SA & 176 & 7289 & 27 & 71 & 33 & 21 & 9 & 45.27 & 34 & 21 & 13 & 275 & 0.487 & 9 \\
\hline 16. & Hershelle Gibbs & SA & 154 & 6167 & 35 & 61 & 25 & 18 & 8 & 41.95 & 26 & 14 & 11 & 228 & 0.399 & 19 \\
\hline 17. & Graeme Smith & SA & 205 & 9265 & 31 & 72 & 40 & 44 & 5 & 48.26 & 38 & 27 & 11 & 277 & 0.554 & 4 \\
\hline 18. & Marvan Atapattu & SL & 156 & 5502 & 22 & 58 & 29 & 22 & 10 & 39.02 & 17 & 16 & 22 & 249 & 0.349 & 21 \\
\hline 19 & Tillakaratne Dilshan & SL & 145 & 5492 & 30 & 48 & 29 & 19 & 8 & 40.99 & 23 & 16 & 14 & 193 & 0.372 & 20 \\
\hline 20. & Gordon Greenidge & WI & 185 & 7558 & 24 & 72 & 31 & 35 & 7 & 44.72 & 34 & 19 & 11 & 226 & 0.451 & 12 \\
\hline \multirow[t]{2}{*}{21.} & Desmond Haynes & WI & 202 & 7487 & 31 & 70 & 37 & 27 & 12 & 42.3 & 39 & 18 & 10 & 184 & 0.431 & 15 \\
\hline & & $w_{j}$ & 0.128 & 0.125 & 0.081 & 0.059 & 0.040 & 0.068 & 0.055 & 0.099 & 0.090 & 0.099 & 0.056 & 0.100 & & \\
\hline
\end{tabular}

It can be revealed from Table 1 that Alastair Cook of England and Sunil Gavaskar of India occupy the top positions in the ranking list of the openers. Hence, they are unanimously included in the World XI Test cricket team as the two opening batsmen. They also virtually satisfy the requirement of the left and right handed batting combination in the team. Mathew Hayden (AUS) and Graeme Smith (SA) respectively are at the third and fourth positions in the ranking list of the openers. The roles of the batsmen at the third, fourth and fifth positions in the Test batting order are also important as they have to face an older ball which is likely to turn and will be responsible to make a competitive score in the match. They must be good stroke players and have the ability to attack, consolidate or defend according to the prevailing circumstances in the match. If the openers lose their wickets in the early stage of the innings, these top order batsmen must bear the responsibility to solidify the team's innings. Tables 2 , 3 and 4 respectively show the lists of the Test players shortlisted for the third (with minimum 120 innings), fourth (with minimum 140 innings) and fifth positions (with minimum 130 innings) of the proposed World XI Test team. The list of the shortlisted players for the third position in batting order has 14 cricketers (four from Australia, three from West Indies, two from England, two from India, one each from South Africa, Sri Lanka and Pakistan). Similarly, in Table 3, there are 17 alternative batsmen (four from England, three from Pakistan, two each from Australia, India, New Zealand, West Indies and Sri Lanka) identified for the fourth position in the batting order of the World XI Test team. There are also 17 cricketers in Table 4 (four from England, three from India, three from Pakistan, two from Sri Lanka, two from West Indies, and one each from Australia, New Zealand and South Africa) shortlisted for the fifth position in the batting order. For all these three batting positions, based on the shortlisted players' performance data, the corresponding values of the criteria weights are estimated using entropy method, and it is observed that maximum importance is provided to the number of innings 
played and total runs scored by a cricketer. The TOPSIS method-based analysis identifies Rahul Dravid from India for the third, Sachin Tendulkar also from India for the fourth and Shivnarine Chanderpaul from West Indies for the fifth positions in the batting order of the proposed World XI Test team.

Table 2

List of number 3 position players with minimum 120 Test innings

\begin{tabular}{|c|c|c|c|c|c|c|c|c|c|c|c|c|c|c|c|c|}
\hline Sl. No. & Player & CUN & INN & RUN & BWD & CGT & $\mathrm{CB}$ & LBW & ODM & AVG & $50 \mathrm{~s}$ & $100 \mathrm{~s}$ & DUCK & $\mathrm{HS}$ & Score & Rank \\
\hline 1. & Neil Harvey & AUS & 137 & 6149 & 34 & 52 & 20 & 17 & 4 & 48.42 & 24 & 21 & 7 & 205 & 0.248 & 8 \\
\hline 2. & Ian Chappell & AUS & 136 & 5345 & 21 & 51 & 28 & 18 & 8 & 42.42 & 26 & 14 & 11 & 196 & 0.186 & 11 \\
\hline 3. & David Boon & AUS & 190 & 7422 & 32 & 76 & 28 & 25 & 9 & 43.66 & 32 & 21 & 16 & 200 & 0.354 & 5 \\
\hline 4. & Ricky Ponting & AUS & 287 & 13378 & 36 & 111 & 42 & 47 & 22 & 51.85 & 62 & 41 & 17 & 257 & 0.840 & 2 \\
\hline 5. & Tom Graveney & ENG & 123 & 4882 & 26 & 49 & 18 & 9 & 8 & 44.38 & 20 & 11 & 8 & 258 & 0.178 & 13 \\
\hline 6. & Mark Butcher & ENG & 131 & 4288 & 12 & 51 & 24 & 26 & 11 & 34.58 & 23 & 8 & 10 & $173^{*}$ & 0.141 & 14 \\
\hline 7. & Dilip Vengsarkar & IND & 185 & 6868 & 16 & 75 & 45 & 19 & 8 & 42.13 & 35 & 17 & 15 & 166 & 0.332 & 6 \\
\hline 8. & Rahul Dravid & IND & 286 & 13288 & 55 & 87 & 64 & 34 & 14 & 52.31 & 63 & 36 & 8 & 270 & 0.869 & 1 \\
\hline 9. & Zaheer Abbas & PAK & 124 & 5062 & 21 & 43 & 30 & 13 & 6 & 44.8 & 20 & 12 & 10 & 274 & 0.178 & 12 \\
\hline 10. & Kumar Sangakkara & SL & 233 & 12400 & 24 & 118 & 44 & 19 & 11 & 57.41 & 52 & 38 & 11 & 319 & 0.758 & 3 \\
\hline 11. & Hashim Amla ${ }^{* *}$ & SA & 183 & 8281 & 31 & 55 & 42 & 32 & 9 & 49 & 35 & 26 & 10 & $311^{*}$ & 0.434 & 4 \\
\hline 12. & Richie Richardson & WI & 146 & 5949 & 20 & 59 & 24 & 26 & 5 & 44.4 & 27 & 16 & 8 & 194 & 0.226 & 10 \\
\hline 13. & Rohan Kanhai & WI & 137 & 6227 & 22 & 69 & 18 & 16 & 6 & 47.53 & 28 & 15 & 7 & 256 & 0.241 & 9 \\
\hline \multirow[t]{2}{*}{14.} & Ramnaresh Sarwan & WI & 154 & 5842 & 17 & 67 & 21 & 31 & 10 & 40.01 & 31 & 15 & 12 & & & \\
\hline & till 28th August, $2017^{* *}$ & $w_{j}$ & 0.226 & 0.169 & 0.014 & 0.038 & 0.022 & 0.023 & 0.010 & 0.036 & 0.197 & 0.121 & 0.051 & & & \\
\hline
\end{tabular}

Table 3

List of number 4 position players with minimum 140 Test innings

\begin{tabular}{|c|c|c|c|c|c|c|c|c|c|c|c|c|c|c|c|c|}
\hline S1. No. & Player & CUN & INN & RUN & BWD & CGT & $\mathrm{CB}$ & LBW & ODM & AVG & $50 \mathrm{~s}$ & $100 \mathrm{~s}$ & DUCK & HS & Score & Rank \\
\hline 1. & Greg Chappell & AUS & 151 & 7110 & 20 & 66 & 21 & 16 & 9 & 53.86 & 31 & 24 & 12 & $247^{*}$ & 0.369 & 12 \\
\hline 2. & Allan Border & AUS & 265 & 11174 & 53 & 79 & 52 & 16 & 21 & 50.56 & 63 & 27 & 11 & 205 & 0.480 & 4 \\
\hline 3. & Wally Hammond & ENG & 140 & 7249 & 38 & 53 & 9 & 12 & 12 & 58.46 & 24 & 22 & 4 & $336^{*}$ & 0.404 & 9 \\
\hline 4. & David Gower & ENG & 204 & 8231 & 28 & 69 & 49 & 36 & 4 & 44.25 & 39 & 18 & 7 & 215 & 0.383 & 10 \\
\hline 5. & Nasser Hussain & ENG & 171 & 5764 & 20 & 56 & 44 & 34 & 1 & 37.19 & 33 & 14 & 14 & 207 & 0.313 & 16 \\
\hline 6. & Kevin Pietersen & ENG & 181 & 8181 & 28 & 71 & 36 & 31 & 7 & 47.29 & 35 & 23 & 10 & 227 & 0.369 & 13 \\
\hline 7. & Gundappa Vishwanath & IND & 155 & 6080 & 41 & 50 & 31 & 16 & 7 & 41.93 & 35 & 14 & 10 & 222 & 0.307 & 17 \\
\hline 8. & Sachin Tendulkar & IND & 329 & 15921 & 54 & 127 & 42 & 63 & 10 & 53.79 & 68 & 51 & 14 & $248^{*}$ & 0.643 & 1 \\
\hline 9. & Stephen Fleming & $\mathrm{NZ}$ & 189 & 7172 & 24 & 80 & 35 & 28 & 12 & 40.07 & 46 & 9 & 16 & $274^{*}$ & 0.327 & 15 \\
\hline 10. & Ross Taylor $^{* *}$ & $\mathrm{NZ}$ & 146 & 6030 & 16 & 49 & 25 & 30 & 8 & 47.11 & 27 & 16 & 12 & 290 & 0.339 & 14 \\
\hline 11. & Javed Miandad & PAK & 189 & 8832 & 21 & 64 & 38 & 33 & 12 & 52.57 & 43 & 23 & 6 & $280^{*}$ & 0.437 & 6 \\
\hline 12. & Inzamam-Ul-Haq & PAK & 200 & 8830 & 22 & 83 & 26 & 34 & 13 & 49.61 & 46 & 25 & 15 & 329 & 0.436 & 7 \\
\hline 13. & Younis Khan & PAK & 213 & 10099 & 27 & 74 & 40 & 46 & 7 & 52.06 & 33 & 34 & 19 & 313 & 0.446 & 5 \\
\hline 14. & Aravinda De Silva & SL & 159 & 6361 & 13 & 76 & 29 & 24 & 6 & 42.98 & 22 & 20 & 7 & 267 & 0.371 & 11 \\
\hline 15. & Mahela Jayawardene & SL & 252 & 11814 & 29 & 102 & 65 & 33 & 8 & 49.85 & 50 & 34 & 15 & 374 & 0.556 & 2 \\
\hline 16. & Viv Richards & WI & 182 & 8540 & 36 & 71 & 35 & 21 & 7 & 50.24 & 45 & 24 & 10 & 291 & 0.415 & 8 \\
\hline \multirow[t]{2}{*}{17.} & Brian Lara & WI & 232 & 11953 & 36 & 93 & 51 & 37 & 9 & 52.89 & 48 & 34 & 17 & 400 & 0.5419 & 3 \\
\hline & & $w_{j}$ & 0.142 & 0.154 & 0.067 & 0.040 & 0.055 & 0.040 & 0.037 & 0.063 & 0.101 & 0.087 & 0.075 & 0.138 & & \\
\hline
\end{tabular}

Table 4

List of number 5 position players with minimum 130 Test innings

\begin{tabular}{|c|c|c|c|c|c|c|c|c|c|c|c|c|c|c|c|c|}
\hline $\begin{array}{l}\text { Sl. } \\
\text { No. }\end{array}$ & Player & CUN & INN & RUN & BWD & CGT & $\mathrm{CB}$ & LBW & ODM & AVG & $50 \mathrm{~s}$ & $100 \mathrm{~s}$ & DUCK & HS & Score & Rank \\
\hline 1. & Michael Clarke & AUS & 198 & 8643 & 37 & 73 & 35 & 19 & 12 & 49.11 & 27 & 28 & 9 & 329 & 0.432 & 8 \\
\hline 2. & Colin Cowdrey & ENG & 188 & 7624 & 31 & 74 & 42 & 19 & 7 & 44.07 & 38 & 22 & 9 & 182 & 0.437 & 7 \\
\hline 3. & Mike Gatting & ENG & 138 & 4409 & 34 & 39 & 14 & 31 & 6 & 35.56 & 21 & 10 & 16 & 207 & 0.309 & 17 \\
\hline 4. & Graham Thorpe & ENG & 179 & 6744 & 27 & 70 & 23 & 22 & 9 & 44.66 & 39 & 16 & 12 & $200^{*}$ & 0.416 & 10 \\
\hline 5. & Ian Bell & ENG & 205 & 7727 & 33 & 71 & 45 & 25 & 6 & 42.69 & 46 & 22 & 14 & 235 & 0.458 & 5 \\
\hline 6. & $\begin{array}{l}\text { Mohammad } \\
\text { Azharuddin }\end{array}$ & IND & 147 & 6215 & 19 & 70 & 23 & 18 & 6 & 45.04 & 21 & 22 & 5 & 199 & 0.428 & 9 \\
\hline 7. & Sourav Ganguly & IND & 188 & 7212 & 26 & 85 & 29 & 23 & 8 & 42.18 & 35 & 16 & 13 & 239 & 0.405 & 12 \\
\hline 8. & VVS Laxman & IND & 225 & 8781 & 39 & 83 & 35 & 21 & 13 & 45.97 & 56 & 17 & 14 & 281 & 0.492 & 2 \\
\hline 9. & Nathan Astle & $\mathrm{NZ}$ & 137 & 4702 & 14 & 58 & 29 & 19 & 7 & 37.02 & 24 & 11 & 11 & 222 & 0.358 & 15 \\
\hline 10. & Saleem Malik & PAK & 154 & 5768 & 31 & 58 & 19 & 19 & 5 & 43.7 & 29 & 15 & 12 & 237 & 0.376 & 13 \\
\hline 11. & Mohammad Yousuf & PAK & 156 & 7530 & 20 & 57 & 35 & 20 & 12 & 52.29 & 33 & 24 & 11 & 223 & 0.410 & 11 \\
\hline 12. & Misbah-Ul-Haq & PAK & 132 & 5222 & 9 & 46 & 27 & 26 & 4 & 46.63 & 39 & 10 & 9 & $161^{*}$ & 0.447 & 6 \\
\hline 13. & Ab De Villiers ${ }^{* *}$ & SA & 176 & 8074 & 31 & 67 & 31 & 23 & 8 & 50.46 & 39 & 21 & 7 & $278^{*}$ & 0.476 & 3 \\
\hline 14. & Arjuna Ranatunga & SL & 155 & 5105 & 18 & 70 & 24 & 18 & 13 & 35.7 & 38 & 4 & 12 & $135^{*}$ & 0.349 & 16 \\
\hline 15. & Thilan Samaraweera & SL & 132 & 5462 & 15 & 38 & 27 & 17 & 15 & 48.77 & 30 & 14 & 11 & 231 & 0.365 & 14 \\
\hline 16. & Clive Lloyd & WI & 175 & 7515 & 27 & 72 & 37 & 15 & 10 & 46.68 & 39 & 19 & 4 & $242^{*}$ & 0.471 & 4 \\
\hline 17. & $\begin{array}{c}\text { Shivnarine } \\
\text { Chanderpaul }\end{array}$ & WI & 280 & 11867 & 25 & 98 & 47 & 55 & 6 & 51.37 & 66 & 30 & 15 & $203^{*}$ & 0.631 & 1 \\
\hline & $8^{\text {th }}$ August, 2017 & $w_{j}$ & 0.162 & 0.109 & 0.091 & 0.058 & 0.075 & 0.028 & 0.066 & 0.082 & 0.121 & 0.059 & 0.089 & 0.061 & & \\
\hline
\end{tabular}


The position of a wicketkeeper in a cricket team is particularly crucial because every team wants someone having safe hands behind the wicket, as one mistake in that area can lead a team to defeat. A good and potential wicketkeeper must also keep the morale of his team high by encouraging the bowlers as well as fielders. He is the best person in the team who can visualize the movement of the ball in air and guide his bowlers to bowl accordingly. A wicketkeeper is also expected to at least bat reasonably well in the middle order. Table 5 shows a list of 14 candidate wicketkeepers shortlisted based on the criterion to play at least 70 Test matches. It includes 4 wicketkeepers from England, three from Australia, two from India, two from West Indies, two from New Zealand, and one each from Pakistan and South Africa. For a wicketkeeper, the number of tests played is more important than the number of innings as all the related statistics are usually expressed with respect to the number of Test matches. The performance of all these 15 wicketkeepers is now evaluated with respect to 14 criteria as number of Test matches (MTC), number of catches taken (CTC), number of stumpings (STP), RUN, BWD, CGT, CB, LBW, ODM, AVG, 50s, 100s, DUCK and HS. These 14 evaluation criteria are again divided into two groups, i.e. beneficial (MTC, CTC, STP, RUN, AVG, 50s, 100s and HS) and non-beneficial (BWD, CGT, CB, LBW, ODM and DUCK) based on their effects on the decision making process. The corresponding TOPSIS scores for the 15 wicketkeepers are now determined, as exhibited in Table 5, which finally lead to their ranking order. It is noticed that Adam Gilchrist from Australia is at the top most position of the list with a TOPSIS score of 0.675 , followed by Alec Stewart of England with a score of 0.520. Hence, Adam Gilchrist is chosen to be the wicketkeeper of the proposed World XI Test cricket team.

Table 5

List of wicketkeepers with minimum 70 Tests

\begin{tabular}{ccccccccc}
\hline S1. No. & Player & CUN & MTC & CTC & STP & RUN & BWD & CGT \\
\hline 1. & Rod Marsh & AUS & 96 & 343 & 12 & 3633 & 27 & 67 \\
2. & Ian Healy & AUS & 119 & 366 & 29 & 4356 & 16 & 83 \\
3. & Adam Gilchrist & AUS & 96 & 379 & 37 & 5570 & 16 & 64 \\
4. & Godfrey Evans & ENG & 91 & 173 & 46 & 2439 & 36 & 52 \\
5. & Alan Knott & ENG & 95 & 250 & 19 & 4389 & 30 & 57 \\
6. & Alec Stewart & ENG & 133 & 227 & 14 & 8463 & 40 & 87 \\
7. & Matt Prior & ENG & 79 & 243 & 13 & 4099 & 20 & 50 \\
8. & Syed Kirmani & IND & 88 & 160 & 38 & 2759 & 29 & 42 \\
9. & M. Singh Dhoni & IND & 90 & 256 & 38 & 4876 & 15 & 62 \\
10. & Adam Parore & NZ & 78 & 194 & 7 & 2865 & 8 & 47 \\
11. & B. Mccullum & NZ & 101 & 167 & 11 & 6453 & 29 & 73 \\
12. & Wasim Bari & PAK & 81 & 201 & 27 & 1366 & 19 & 32 \\
13. & Mark Boucher & SA & 146 & 532 & 23 & 5515 & 40 & 75 \\
14. & Jeff Dujon & WI & 81 & 267 & 5 & 3322 & 21 & 45 \\
15. & Denesh Ramdin & WI & 74 & 202 & 11 & 2898 & 23 & 46 \\
\hline & & $w_{j}$ & 0.11 & 0.12 & 0.09 & 0.06 & 0.07 & 0.05 \\
\hline
\end{tabular}

Table 5

List of wicketkeepers with minimum 70 Tests

\begin{tabular}{ccccccccccc}
\hline Sl. No. & CB & LBW & ODM & AVG & 50 s & 100 s & DUCK & HS & Score & Rank \\
\hline 1. & 23 & 13 & 7 & 26.52 & 16 & 3 & 12 & 132 & 0.325 & 12 \\
2. & 35 & 18 & 7 & 27.4 & 22 & 4 & 18 & $161^{*}$ & 0.426 & 6 \\
3. & 20 & 12 & 5 & 47.61 & 26 & 17 & 14 & $204^{*}$ & 0.675 & 1 \\
4. & 15 & 6 & 10 & 20.5 & 8 & 2 & 17 & 104 & 0.348 & 10 \\
5. & 18 & 21 & 8 & 32.75 & 30 & 5 & 8 & 135 & 0.372 & 8 \\
6. & 40 & 40 & 7 & 39.55 & 45 & 15 & 14 & 190 & 0.520 & 2 \\
7. & 18 & 7 & 7 & 40.19 & 28 & 7 & 13 & $131^{*}$ & 0.387 & 7 \\
8. & 11 & 12 & 8 & 27.05 & 12 & 2 & 7 & $102^{*}$ & 0.350 & 9 \\
9. & 32 & 12 & 7 & 38.09 & 33 & 6 & 10 & 224 & 0.500 & 3 \\
10. & 25 & 20 & 9 & 26.28 & 14 & 2 & 6 & 110 & 0.288 & 14 \\
11. & 27 & 33 & 5 & 38.64 & 31 & 12 & 14 & 302 & 0.479 & 5 \\
12. & 19 & 10 & 6 & 15.88 & 6 & 0 & 19 & 85 & 0.280 & 15 \\
13. & 35 & 25 & 7 & 30.3 & 35 & 5 & 17 & 125 & 0.494 & 4 \\
14. & 15 & 17 & 6 & 31.94 & 16 & 5 & 8 & 139 & 0.335 & 11 \\
15. & 23 & 18 & 2 & 25.88 & 15 & 4 & 9 & 166 & 0.313 & 13 \\
\hline
\end{tabular}


In a cricket team, an all-rounder is that player who can bat as well as bowl. An all-rounder must provide a Test team with the much required balance with his ability to take wickets and score runs. He can act as an extra bowler for his team and also as a good batsman to rescue his team at the time of batting collapse. Thus, an all-rounder can provide the much required rest to the regular bowlers of his team and also support his team with his bat. Table 6 shortlists 14 all-rounders from all the Test playing nations who have scored at least 2000 runs and captured a minimum of 150 wickets. This list of allrounders consists of three players for India, three from New Zealand, two from Australia, two from England, two from South Africa, and one each from Pakistan and West Indies. For evaluation of the performance of all these 14 all-rounders, 18 critical criteria are considered which contain both the measures for the batsmen and bowlers. These criteria are MTC, INN, RUN, number of outs (OUT), AVG, 50s, 100s, DUCK, HS, number of balls bowled (BB), number of maidens (MDN), number of wickets taken (WCK), total runs conceded (RC), bowling average (BAVG), economy rate (ECY), strike rate (STR), number of times five wickets taken in an innings (5W/I) and number of times ten or more wickets taken in a Test match $(10 \mathrm{~W} / \mathrm{M})$. The bowling average is simply the ratio of the total runs conceded to the number of wickets taken. Economy rate is the average number of runs conceded per over by a bowler. The strike rate for a bowler is defined as the average number of balls bowled per wicket taken. Among these 18 evaluation criteria for the all-rounders, MTC, INN, RUN, AVG, 50s, $100 \mathrm{~s}, \mathrm{HS}, \mathrm{BB}, \mathrm{MDN}, \mathrm{WCK}, 5 \mathrm{~W} / \mathrm{I}$ and $10 \mathrm{~W} / \mathrm{M}$ are the beneficial attributes, and the remaining are the non-beneficial performance measures requiring their lower values. As usual, based on the entropy method, the priorities of all these criteria are estimated, as provided in Table 6 .

Table 6

List of all-rounders with minimum 2000 runs and 150 wickets (Part 1)

\begin{tabular}{|c|c|c|c|c|c|c|c|c|c|c|c|}
\hline Sl. No. & Player & CUN & MTC & INN & RUN & OUT & AVG & $50 \mathrm{~s}$ & $100 \mathrm{~s}$ & DUCK & HS \\
\hline 1. & K. Miller & AUS & 55 & 87 & 2958 & 80 & 37 & 13 & 7 & 5 & 147 \\
\hline 2. & R. Benaud & AUS & 63 & 97 & 2201 & 90 & 24.5 & 9 & 3 & 8 & 122 \\
\hline 3. & I. Botham & ENG & 102 & 161 & 5200 & 155 & 33.6 & 22 & 14 & 14 & 208 \\
\hline 4. & A. Flintoff & ENG & 79 & 130 & 3845 & 121 & 31.8 & 26 & 5 & 17 & 167 \\
\hline 5. & K. Dev & IND & 131 & 184 & 5248 & 169 & 31.1 & 27 & 8 & 16 & 163 \\
\hline 6. & R. Shastri & IND & 80 & 121 & 3830 & 107 & 35.8 & 12 & 11 & 9 & 206 \\
\hline 7. & R. Ashwin ${ }^{* *}$ & IND & 52 & 72 & 2035 & 62 & 32.8 & 11 & 4 & 3 & 124 \\
\hline 8. & R. Hadlee & $\mathrm{NZ}$ & 86 & 134 & 3124 & 115 & 27.2 & 15 & 2 & 12 & 151 \\
\hline 9. & C. Cairns & $\mathrm{NZ}$ & 62 & 104 & 3320 & 99 & 33.5 & 22 & 5 & 7 & 158 \\
\hline 10. & D. Vettori & $\mathrm{NZ}$ & 112 & 174 & 4531 & 151 & 30 & 23 & 6 & 20 & 140 \\
\hline 11. & I. Khan & PAK & 88 & 126 & 3807 & 101 & 37.7 & 18 & 6 & 8 & 136 \\
\hline 12. & S. Pollock & SA & 108 & 156 & 3781 & 117 & 32.3 & 16 & 2 & 9 & 111 \\
\hline 13. & J. Kallis & SA & 166 & 280 & 13289 & 240 & 55.4 & 58 & 45 & 16 & 224 \\
\hline \multirow[t]{2}{*}{14.} & G. Sobers & WI & 93 & 160 & 8032 & 139 & 57.8 & 26 & 2 & 12 & 365 \\
\hline & & $w_{j}$ & 0.06 & 0.1 & 0.08 & 0.02 & 0.05 & 0.1 & 0.15 & 0.03 & 0.1 \\
\hline
\end{tabular}

Table 6

List of all-rounders with minimum 2000 runs and 150 wickets (Part 2)

\begin{tabular}{|c|c|c|c|c|c|c|c|c|c|c|c|}
\hline S1. No. & BB & $\mathrm{MDN}$ & WCK & $\mathrm{RC}$ & BAVG & ECY & STR & $5 \mathrm{~W} / \mathrm{I}$ & $10 \mathrm{~W} / \mathrm{M}$ & Score & Rank \\
\hline 1. & 10461 & 337 & 170 & 3906 & 22.98 & 2.24 & 61.54 & 7 & 1 & 0.15 & 11 \\
\hline 2. & 19108 & 805 & 248 & 6704 & 27.03 & 2.11 & 77.05 & 16 & 1 & 0.12 & 14 \\
\hline 3. & 21815 & 788 & 383 & 10878 & 28.4 & 2.99 & 56.96 & 27 & 4 & 0.34 & 3 \\
\hline 4. & 14951 & 506 & 226 & 7410 & 32.79 & 2.97 & 66.15 & 3 & 0 & 0.13 & 13 \\
\hline 5. & 27740 & 1060 & 434 & 12867 & 29.65 & 2.78 & 63.92 & 23 & 2 & 0.24 & 6 \\
\hline 6. & 15751 & 657 & 151 & 6186 & 40.97 & 2.36 & 104.3 & 2 & 0 & 0.19 & 9 \\
\hline 7. & 15314 & 517 & 292 & 7377 & 25.26 & 2.89 & 52.45 & 26 & 7 & 0.31 & 4 \\
\hline 8. & 21918 & 809 & 431 & 9611 & 22.3 & 2.63 & 50.85 & 36 & 9 & 0.37 & 2 \\
\hline 9. & 11698 & 414 & 218 & 6410 & 29.4 & 3.29 & 53.66 & 13 & 1 & 0.14 & 12 \\
\hline 10. & 28814 & 1197 & 362 & 12441 & 34.37 & 2.59 & 79.6 & 20 & 3 & 0.23 & 7 \\
\hline 11. & 19458 & 727 & 362 & 8258 & 22.81 & 2.55 & 53.75 & 23 & 6 & 0.30 & 5 \\
\hline 12. & 24353 & 1211 & 421 & 9733 & 23.12 & 2.4 & 57.85 & 16 & 1 & 0.16 & 10 \\
\hline 13. & 20232 & 848 & 292 & 9535 & 32.65 & 2.83 & 69.29 & 5 & 0 & 0.64 & 1 \\
\hline \multirow{2}{*}{14.} & 21599 & 974 & 235 & 7999 & 34.04 & 2.22 & 91.91 & 6 & 0 & 0.23 & 8 \\
\hline & 0.04 & 0.04 & 0.04 & 0.04 & 0.02 & 0.03 & 0.02 & 0.06 & 0.12 & & \\
\hline
\end{tabular}


The corresponding TOPSIS scores are calculated and the candidate all-rounders are then ranked depending on the descending values of their TOPSIS scores. It can be revealed from this table that Jacques Kallis from South Africa emerges out as the best all-rounder for inclusion in the proposed World XI Test cricket team. Richard Hadlee of New Zealand is the second best all-rounder. In a Test match, the main goal of any bowler is to take the wicket of the opponent batsman, followed by trying to prevent him from scoring runs. Depriving a batsman from scoring runs often makes him frustrated and compels him to attempt risky shots to score. In addition, stopping the batsman from scoring runs keeps him at the crease to face consecutive balls which may be a tactical strategy. The success of a Test cricket team primarily lies on its skilled fast bowlers, with spinners in the support roles. At the start of an innings in a Test match, two fast bowlers/pacers/seamers share the bowling attack for the fielding side while trying to exploit the early favourable condition of the pitch. At this time, the ball is used to move fast and swing in air, causing difficulty for the opponent's opening batsmen to play and score runs. If these two fast bowlers can make a breakthrough of the opponent's innings by taking a couple of wickets at the beginning of the innings, the opponent team will be under tremendous pressure and will face a huge difficulty to recover from that awkward situation. In the history of International Test cricket, there exist hundreds of fast bowlers sharing the responsibilities to start the bowling attacks for their respective countries. While trimming down these large number of fast bowlers into a convenient figure, a list of 23 fast bowlers is prepared in Table 7 based on the criterion that they should have played at least 70 Test matches for their countries. This list contains six fast bowlers from Australia, four from England, four from South Africa, three from West Indies, two from India, two from Pakistan, and one each from New Zealand and Sri Lanka. The performance of all these 23 fast blowers is now evaluated based on ten criteria, i.e. MTC, BB, MDN, WCK, RC, BAVG, ECY, STR, 5W/I and 10W/M. The weights of these criteria are also determined while employing entropy method and it is revealed that number of matches played by a fast bowler has the maximum importance, followed by the number of maidens he bowled and number of 10 or more wickets he took in a Test match. The corresponding TOPSIS scores are computed as shown in Table 7 based on which the considered fast bowlers are subsequently ranked. Glenn McGrath of Australia and Courtney Walsh of West Indies occupy the top two positions in the ranking of the candidate fast bowlers, and can be considered for inclusion in the all-time World XI Test cricket team. The third and fourth positions are respectively captured by Wasim Akram of Pakistan and James Anderson of England.

Table 7

List of fast bowlers (pacers) with minimum 70 Tests

\begin{tabular}{|c|c|c|c|c|c|c|c|c|c|c|c|c|c|c|}
\hline Sl. No. & Player & CUN & MTC & $\mathrm{BB}$ & MDN & WKT & $\mathrm{RC}$ & BAVG & ECY & STR & $5 \mathrm{~W} / \mathrm{I}$ & $10 \mathrm{~W} / \mathrm{M}$ & Score & Rank \\
\hline 1. & Dennis Lillee & AUS & 70 & 18467 & 652 & 355 & 8493 & 23.92 & 2.76 & 52.02 & 23 & 7 & 0.557 & 5 \\
\hline 2. & Craig Mcdermott & AUS & 71 & 16586 & 583 & 291 & 8332 & 28.63 & 3.01 & 57.00 & 14 & 2 & 0.232 & 15 \\
\hline 3. & Glenn Mcgrath & AUS & 124 & 29248 & 1470 & 563 & 12186 & 21.64 & 2.5 & 51.95 & 29 & 3 & 0.664 & 1 \\
\hline 5. & Brett Lee & AUS & 76 & 16531 & 547 & 310 & 9555 & 30.82 & 3.47 & 53.33 & 10 & 0 & 0.107 & 22 \\
\hline 6. & Mitchell Johnson & AUS & 73 & 16001 & 514 & 313 & 8892 & 28.41 & 3.33 & 51.12 & 12 & 3 & 0.288 & 14 \\
\hline 7. & Brian Statham & ENG & 70 & 16056 & 595 & 252 & 6261 & 24.85 & 2.34 & 63.71 & 9 & 1 & 0.166 & 18 \\
\hline 9. & James Anderson ${ }^{* *}$ & ENG & 127 & 27862 & 1142 & 495 & 13684 & 27.64 & 2.95 & 56.29 & 23 & 3 & 0.590 & 4 \\
\hline 10. & Stuart Broad** & ENG & 107 & 22003 & 828 & 385 & 11009 & 28.59 & 3 & 57.15 & 15 & 2 & 0.371 & 12 \\
\hline 11. & Zaheer Khan & IND & 92 & 18785 & 624 & 311 & 10247 & 32.95 & 3.27 & 60.4 & 11 & 1 & 0.200 & 16 \\
\hline 12. & Ishant Sharma** & IND & 77 & 14775 & 474 & 218 & 8051 & 36.93 & 3.27 & 67.78 & 7 & 1 & 0.117 & 21 \\
\hline 13. & Chris Martin & NZ & 71 & 14026 & 486 & 233 & 7839 & 33.64 & 3.35 & 60.2 & 10 & 1 & 0.122 & 20 \\
\hline 14. & Wasim Akram & PAK & 104 & 22627 & 871 & 414 & 9779 & 23.62 & 2.59 & 54.65 & 25 & 5 & 0.597 & 3 \\
\hline 15. & Waqar Younis & PAK & 87 & 16224 & 516 & 373 & 8788 & 23.56 & 3.25 & 43.5 & 22 & 5 & 0.458 & 9 \\
\hline 16. & Allan Donald & $\mathrm{SA}$ & 72 & 15519 & 661 & 330 & 7344 & 22.25 & 2.84 & 47.03 & 20 & 3 & 0.343 & 13 \\
\hline 18. & Dale Steyn** & SA & 85 & 17286 & 622 & 417 & 9303 & 22.31 & 3.23 & 41.45 & 26 & 5 & 0.493 & 7 \\
\hline 19. & Morne Morkel $^{* *}$ & SA & 78 & 15129 & 540 & 272 & 7893 & 29.02 & 3.13 & 55.62 & 6 & 0 & 0.096 & 23 \\
\hline 20. & Chaminda Vaas & SL & 111 & 23438 & 895 & 355 & 10501 & 29.58 & 2.69 & 66.02 & 12 & 2 & 0.391 & 11 \\
\hline 21. & Malcolm Marshall & WI & 81 & 17584 & 613 & 376 & 7876 & 20.95 & 2.69 & 46.77 & 22 & 4 & 0.422 & 10 \\
\hline 22. & Courtney Walsh & WI & 132 & 30019 & 1144 & 519 & 12684 & 24.44 & 2.54 & 57.84 & 22 & 3 & 0.604 & 2 \\
\hline \multirow[t]{2}{*}{23.} & Curtly Ambrose & WI & 98 & 22103 & 1001 & 405 & 8502 & 20.99 & 2.31 & 54.58 & 22 & 3 & 0.494 & 6 \\
\hline & & $w_{j}$ & 0.184 & 0.142 & 0.162 & 0.082 & 0.044 & 0.041 & 0.080 & 0.054 & 0.087 & 0.123 & & \\
\hline
\end{tabular}

** till 28th August, 2017 
Like the fast bowlers in a Test team, the spinners are also responsible in taking the opponent's wickets and restricting them to a moderate score which will be easy to chase. A spinner in a cricket team can turn the ball while pitching it on the cracks and footmarks of the fast bowlers on the crease. The world of cricket has also witnessed some remarkable spinners famous for their bowling and wicket taking abilities. From those, a pool of 21 spinners is developed in Table 8, shortlisting them based on the criterion that they should have played at least 50 Test matches for their respective counties. This list of 21 alternative spinners consists of seven spinners from England, five from India, four from Pakistan, two from Australia, two from Sri Lanka and one from West Indies. The procedure for their performance evaluation is same as that for the fast bowlers. When they are ranked depending on their computed TOPSIS scores, Muttiah Muralitharan from Sri Lanka and Shane Warne from Australia are identified as the top two spinners for inclusion in the World XI Test team. Basically, Muttiah Muralitharan supersedes all his competitors with a TOPSIS score of as high as 0.914. Anil Kumble of India and Rangana Herath of Sri Lanka respectively occupy the third and fourth positions in the derived ranking list. Muttiah Muralitharan has been renowned for his great off-break bowling and Shane Warne has been the king of leg-spin bowling. Their inclusions in the World XI Test team also fulfil the much desired off-spinner and leg-spinner combination in a cricket team.

Table 8

List of spinners with minimum 50 Tests

\begin{tabular}{|c|c|c|c|c|c|c|c|c|c|c|c|c|c|c|}
\hline Sl. No. & Player & CUN & MTCS & BB & MDN & WCK & $\mathrm{RC}$ & AVG & ECY & STR & $5 \mathrm{~W} / \mathrm{I}$ & $10 \mathrm{~W} / \mathrm{M}$ & Score & Rank \\
\hline 1. & Shane Warne & AUS & 145 & 40705 & 1762 & 708 & 17995 & 25.42 & 2.65 & 57.49 & 37 & 10 & 0.584 & 2 \\
\hline 2. & Nathon Lyon $^{* *}$ & AUS & 67 & 15565 & 471 & 247 & 8245 & 33.38 & 3.18 & 63.02 & 11 & 1 & 0.119 & 15 \\
\hline 3. & Ray Illingworth & ENG & 61 & 11784 & 702 & 122 & 3807 & 31.2 & 1.94 & 96.59 & 3 & 0 & 0.101 & 18 \\
\hline 4. & Derek Underwood & ENG & 86 & 21862 & 1239 & 297 & 7674 & 25.84 & 2.11 & 73.61 & 17 & 6 & 0.303 & 6 \\
\hline 5. & Phil Edmonds & ENG & 51 & 12028 & 613 & 125 & 4273 & 34.18 & 2.13 & 96.22 & 2 & 0 & 0.088 & 20 \\
\hline 6. & John Emburey & ENG & 64 & 15391 & 741 & 147 & 5646 & 38.41 & 2.2 & 104.7 & 6 & 0 & 0.104 & 17 \\
\hline 7. & Ashley Giles & ENG & 54 & 12180 & 397 & 143 & 5806 & 40.6 & 2.86 & 85.17 & 5 & 0 & 0.074 & 21 \\
\hline 8. & Monty Panesar & ENG & 50 & 12475 & 468 & 167 & 5797 & 34.71 & 2.79 & 74.7 & 12 & 2 & 0.118 & 16 \\
\hline 9. & Graeme Swann & ENG & 60 & 15349 & 493 & 255 & 7642 & 29.97 & 2.99 & 60.19 & 17 & 3 & 0.169 & 10 \\
\hline 10. & B. S. Chandrasekhar & IND & 58 & 15963 & 584 & 242 & 7199 & 29.75 & 2.71 & 65.96 & 16 & 2 & 0.148 & 11 \\
\hline 11. & Srinivas Venkataraghavan & IND & 57 & 14877 & 696 & 156 & 5634 & 36.12 & 2.27 & 95.37 & 3 & 1 & 0.102 & 19 \\
\hline 12. & Bishan Singh Bedi & IND & 67 & 21364 & 1096 & 266 & 7637 & 28.71 & 2.14 & 80.32 & 14 & 1 & 0.183 & 9 \\
\hline 13. & Anil Kumble & IND & 132 & 40850 & 1575 & 619 & 18355 & 29.65 & 2.7 & 65.99 & 35 & 8 & 0.514 & 3 \\
\hline 14. & Harbhajan Singh & IND & 103 & 28580 & 869 & 417 & 13537 & 32.46 & 2.84 & 68.54 & 25 & 5 & 0.326 & 5 \\
\hline 15. & Iqbal Qasim & PAK & 50 & 13019 & 649 & 171 & 4807 & 28.11 & 2.22 & 76.13 & 8 & 2 & 0.122 & 14 \\
\hline 16. & Abdul Qadir & PAK & 67 & 17126 & 608 & 236 & 7742 & 38.81 & 2.71 & 72.57 & 15 & 5 & 0.215 & 8 \\
\hline 17. & Mushtaq Ahmed & PAK & 52 & 12526 & 405 & 185 & 6100 & 32.97 & 2.92 & 67.71 & 10 & 3 & 0.136 & 13 \\
\hline 18. & Danish Kaneria & PAK & 61 & 17697 & 517 & 261 & 9082 & 34.8 & 3.08 & 67.8 & 15 & 2 & 0.147 & 12 \\
\hline 19. & Muttiah Muralitharan & $\mathrm{SL}$ & 132 & 44039 & 1792 & 800 & 18180 & 22.73 & 2.48 & 55.05 & 67 & 22 & 0.915 & 1 \\
\hline 20. & Rangana Herath" ${ }^{* *}$ & SL & 83 & 23465 & 739 & 389 & 10992 & 28.26 & 2.81 & 60.32 & 31 & 8 & 0.376 & 4 \\
\hline 21. & Lance Gibbs & WI & 79 & 27115 & 1313 & 309 & 8989 & 29.09 & 1.99 & 87.75 & 18 & 2 & 0.248 & 7 \\
\hline & & $w_{j}$ & 0.150 & 0.151 & 0.118 & 0.132 & 0.045 & 0.042 & 0.055 & 0.039 & 0.106 & 0.163 & & \\
\hline
\end{tabular}

After the formation of the all-time best World XI Test cricket team consisting of 11 cricketers, it is the final task to decide the captain of this proposed team. It is observed that among the selected 11 Test players, eight cricketers became the captains of their respective countries. Their captaincy records are provided in Table 9. It is noticed from this table that Adam Gilchrist of Australia and Jacques Kallis of South Africa had encouraging percentages of win in Test matches that they captained. But, their experience as a Test team captain has been miserably poor, even less than in ten Test matches. They basically acted as the stop-gap captains for their respective teams. Hence, it is advised to appoint Alastair Cook of England as the captain of the World XI Test cricket team, along with Rahul Dravid as the vice-captain. Thus, the all-time best World Test team is formed as Alastair Cook (ENG) (c), Sunil Gavaskar (IND), Rahul Dravid (IND) (vc), Sachin Tendulkar (IND), Shivnarine Chanderpaul (WI), Jacques Kallis (SA), Adam Gilchrist (AUS) (wk), Glenn McGrath (AUS), Courtney Walsh (WI), Muttiah Muralitharan (SL) and Shane Warne (AUS). Based on his all round ability to both bat and bowl, Richard Hadlee of New Zealand may be the twelfth man in this team. The ESPN Cricinfo proposed an all-time Test XI team consisting of Jack Hobbs (ENG), Leonard Hutton (ENG), Donald Bradman (AUS), Sachin Tendulkar (IND), Viv Richards (WI), Garry Sobers (WI), Adam Gilchrist (AUS) (wk), Malcolm Marshall (WI), Shane Warne (AUS), Wasim Akram (PAK) and Dennis Lillee 
(AUS) based on their achievements in Test matches. In that all-time Test XI team, there were four players from Australia, three from West Indies, two from England, and one each from India and Pakistan. It was formed based on the opinions of 12 members of the jury (each juror was asked to pick a first XI and a second) and depending on the points allotted to each of the players, a list was prepared consisting of those having the maximum points. As this process was based on the opinions and preferences of the jury members, it is supposed to be not always absolutely free from biasness and personal choices. On the other hand, to mark its $150^{\text {th }}$ anniversary, Wisden Cricketers' Almanack, a cricket reference book published from England, formed another all-time Test XI team comprising Jack Hobbs (ENG), WG Grace (ENG), Donald Bradman (AUS) (c), Sachin Tendulkar (IND), Viv Richards (WI), Garry Sobers (WI), Alan Knott (ENG) (wk), Wasim Akram (PAK), Shane Warne (AUS), Malcolm Marshall (WI) and Sydney Barnes (ENG). This selection process was based on shortlisting 11 players from more than 2,600 people appeared in Test matches across 150 years of the Wisden's life. Points were allocated to each of the players based on their performance in the history of World cricket. The list consisted of four cricketers from England, three from West Indies, two from Australia, one each from India and Pakistan. It was also not at all free of controversy and criticism from the cricket lovers as it included twice any many cricketers from England as compared to Australia. It had only two cricketers from the Asian cricket playing nations. Thus, it is observed that the formation of the two above-mentioned all-time best Test cricket teams has no concrete mathematical foundation and is not free from biasness. Hence, the best World XI Test team which is formed taking into consideration the shortest Euclidean distances of the alternatives from the positive-ideal solutions is more realistic and absolutely free from any involvement of the decision makers. Excepting New Zealand and Pakistan, it includes players from the remaining six Test playing countries, having no biasness towards any particular nation. It also includes some of the cricketers from the lists prepared by ESPN Cricinfo and Wisden.

\section{Table 9}

List of captains for the Test playing countries

\begin{tabular}{ccccccc}
\hline Sl. No. & Player & Matches as captain & Won & Lost & Drawn & \% of win \\
\hline 1. & Alastair Cook (ENG) & 59 & 24 & 22 & 13 & 40.68 \\
2. & Sunil Gavaskar (IND) & 47 & 9 & 8 & 30 & 19.15 \\
3. & Rahul Dravid (IND) & 25 & 8 & 6 & 11 & 32.00 \\
4. & Sachin Tendulkar (IND) & 25 & 4 & 9 & 12 & 16.00 \\
5. & Shivnarine Chanderpaul (WI) & 14 & 1 & 10 & 3 & 7.14 \\
6. & Jacques Kallis (RSA) & 2 & 1 & 1 & 0 & 50.00 \\
7. & Adam Gilchrist (AUS) & 6 & 4 & 1 & 1 & 66.67 \\
\hline. & Courtney Walsh (WI) & 22 & 6 & 7 & 7 & 27.27 \\
\hline
\end{tabular}

\section{Conclusions}

Since over the 100 plus years of Test cricket history, there have been more than 2600 players participated in Test matches for their respective countries. It is thus really a challenging task to try for the formation of the all-time best World XI Test cricket team from the available voluminous database. In this paper, a multi-criteria decision making tool, in the form of TOPSIS method, is adopted in an attempt to form the best World XI Test team taking into consideration all the cricketers from the ten Test playing nations. This huge volume of data containing the numbers of cricketers for each of the positions in the batting and bowling orders is reduced into manageable figures while considering some specific threshold values, i.e. minimum number of innings played (for batsmen), minimum number of Tests played (for wicketkeepers and bowlers), and minimum number of runs scored and wickets taken (for all-rounders). Using TOPSIS method, which is based on ranking of the considered alternatives depending on their distances from the ideal solution, the best World XI Test cricket team is thus formed comprising Alastair Cook (ENG) (c), Sunil Gavaskar (IND), Rahul Dravid (IND) (vc), Sachin Tendulkar (IND), Shivnarine Chanderpaul (WI), Jacques Kallis (RSA), Adam Gilchrist (AUS) (wk), Glenn McGrath (AUS), Courtney Walsh (WI), Muttiah Muralitharan (SL) and Shane Warne (AUS). 
This Test team is supposed to be more practical and free from any human judgement. The TOPSIS method can also be applied to form the all-time best World One-day and T20 cricket teams. It can practically be employed to find out the best possible combination of players for any multi-player game for any country.

\section{References}

Ahmed, F., Jindal, A., Deb, K. (2011). Cricket team selection using evolutionary multi-objective optimization. In Proc. of $2^{\text {nd }}$ International Conference on Swarm, Evolutionary, and Memetic Computing, India, 71-78.

Aqil Burney, S.M., Mahmood, N., Rizwan, K., Amjad, U. (2012). A generic approach for team selection in multi-player games using genetic algorithm. International Journal of Computer Applications, 40(17), 11-17.

Bagheri, M., Shojaei, P \& Khorami, M. (2018). A comparative survey of the condition of tourism infrastructure in Iranian provinces using VIKOR and TOPSIS. Decision Science Letters, 7(1), 87102.

Barr, G. D. I., Kantor, B. S. (2004). A criterion for comparing and selecting batsmen in limited overs cricket. Journal of the Operational Research Society, 55(12), 1266-1274.

Beaudoin, D., Swartz, T. (2003). The best batsmen and bowlers in one-day cricket. South African Statistical Journal, 37(2), 203-222.

Behzadian, M., Otaghsara, S.K., Yazdani, M., Ignatius, J. (2012). A state-of-the-art survey of TOPSIS applications. Expert Systems with Applications, 39(17), 13051-13069.

Bhattacharjee, D., Saikia, H. (2014). On performance measurement of cricketers and selecting an optimum balanced team. International Journal of Performance Analysis in Sports, 14(1), 262-275.

Daniyal, M., Nawaz, T., Mubeen, I., Aleem, M. (2012). Analysis of batting performance in cricket using individual and moving range (MR) control charts. International Journal of Sports Science and Engineering, 6(4), 195-202.

Hwang, C-L., Yoon, K. (1981). Multiple Attribute Decision Making: Methods and Applications A State-of-the-Art Survey. Springer-Verlag, Berlin Heidelberg.

Gaur, P. K., Bhattacharjee, D. (2016). On finding the most compatible batting average. Journal of Applied Quantitative Methods, 11(3), 50-60.

Irvine, S., Kennedy, R. (2017). Analysis of performance indicators that most significantly affect International Twenty20 cricket. International Journal of Performance Analysis in Sports, 17(3), 350-359.

Kamble, A.G., Rao, R.V., Kale A.V., Samant, S.P. (2011). Selection of cricket players using analytical hierarchy process. International Journal of Sports Science and Engineering, 5(4), 207-212.

Kimber, A. (1993). A graphical display for comparing bowlers in cricket. An International Journal for Teachers, 15(3), 84-86.

Lemmer, H. H. (2011). Performance measures for wicket keepers in cricket. South African Journal for Research in Sport, Physical Education and Recreation, 33(3), 89-102.

Ovens, M., Bukiet, B. (2006). A mathematical modelling approach to one-day cricket batting orders. Journal of Sports Science and Medicine, 5(4), 495-502.

Saikia, H., Bhattacharjee, D., Radhakrishnan, U. K. (2016). A new model for player selection in cricket. International Journal of Performance Analysis in Sports, 16(1), 373-388.

Sathya, S. S., Jamal, M.S. (2009). Applying genetic algorithm to select an optimal cricket team. In Proc. of International Conference on Advances in Computing, Communication and Control, India, 43-47.

Swartz, T. B., Gill, P.S., Beaudoin, D., deSilva, B.M. (2006). Optimal batting orders in one-day cricket. Computers \& Operations Research, 33(7), 1939-1950.

Rao, R.V. (2007). Decision Making in the Manufacturing Environment using Graph Theory and Fuzzy Multiple Attribute Decision Making Methods. Springer-Verlag, London. 
Tlig, H \& Rebai, A. (2017). A TOPSIS method based on intuitionistic fuzzy values: a case study of North African airports. Management Science Letters, 7(7), 351-358.

Van Staden, P. J. (2009). Comparison of cricketers' bowling and batting performances using graphical displays. Current Science, 96(6), 764-766.

$\mathrm{Xu}, \mathrm{X}$. (2004). A note on the subjective and objective integrated approach to determine attribute weights. European Journal of Operational Research, 156(2), 530-532.

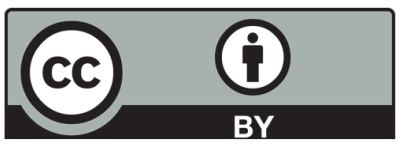

(C) 2019 by the authors; licensee Growing Science, Canada. This is an open access article distributed under the terms and conditions of the Creative Commons Attribution (CC-BY) license (http://creativecommons.org/licenses/by/4.0/). 